Ostrowski D. The Assembly of the Land (Zemskii sobor) as a Representative Institution // Modernizing Muscovy: Reform and Social Change in Seventeenth-Century Russia / Ed. by J. Kotilaine and M. 1 Poe. London, 2004. P. 117-141. Schamiloglu U. The Qaraci Beys of the Late Golden Horde: Notes on the Organization of the Mongol World Empire // Archivum Eurasiae Medii Aevi. 1984. Vol. 4. P. 283-297.

Wittfogel K. A. Oriental Despotism. A Comparative Study of Total Power. New Haven, 1957.

\author{
Charles J. Halperin \\ Russian and East European Institute of Indiana, USA
}

\title{
THE KHAN AND THE ELITE: THE MUSCOVITE PERCEPTION OF THE POLITICAL CULTURE OF THE CRIMEAN KHANATE DURING THE REIGN OF IVAN IV
}

Michael Hope suggested that within the framework of the political culture of the Mongol empire and its successors there were two traditions: the unlimited power of a ruler, such as Chingiz-Khan, and collegial consensual power, such as the qurultai. According to the Moscow embassy books (Crimean affairs) of the reign of Ivan IV, the Moscow court perceived the political culture of the Crimean Khanate, the successor of Ulus Juchi, as consistent with the second paradigm a consensual collegial state.

Keywords: Ivan IV, Muscovy, Crimean Khanate, elite, political culture, consensual, collegiate

\author{
УДК 9.94 ББК 63.3(2)4 DOI 10.25986/IRI.2019.75.1.005 \\ Т. В. Гимон \\ ИВИ РАН, Москва, \\ НОВГОРОДСКИЕ ВААДЫЧНЫЕ ЛЕТОПИСЏЫ \\ ВТОРОЙ ТРЕТИ ХІV - НАЧАЛА ХV в.
}

А. А. Гиппиус выявил в тексте Новгородской I летописи моменты смены архиепископских летописџев, пополнявших летопись в XII - начале XIV в. Аналогичные выводы были сделаны А. Г. Бобровым в отношении текста за XV в. B настояшей статье делается ряд наблюдений над промежуточным текстом, за 1331-1421 г., позволяюших предварительно говорить о том, что в этот период, как и прежде, и впоследствии, летописџы, как правило, сменялись вслед за их патронами - архиепископами.

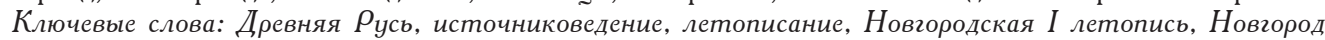

Предпринятый А. А. Гиппиусом [Гиппиус, 1996, с. 13-26; Гиппиус, 2006] систематический анализ языка и стиля статей Новгородской I летописи (далее - H1) за XII - начало XIV в. позволил выявить моменты смены авторов. В большинстве случаев эти моменты совпадают по времени (точно или примерно) со сменами архиепископов, а значит, летописание в Новгороде велось из года в год и было владычным². Как показывает пример пономаря Тимофея (XIII в.), атакже, вероятно,КирикаиГерманаВояты (XIІв.),владычнымилетописцамибыликлирики,исполнявшиепопоручению архиепископов и ряд секретарских обязанностей [Гиппиус, 1992; Гиппиус, 1996, с. 23]. Результаты исследования А. А. Гиппиуса открыли новые возможности как лингвистического, так и источниковедческого исследования новгородской летописи: теперь мы можем сопоставлять язык конкретных летописцев, манеру их работы, круг интересов, взгляды и т. д.

Для XV в. сегментаџию новгородской летописи предложил А. Г. Бобров. «Техническим руководителем» «непрерывно ведушейся летописи» начала XV в. ученый считает Матфея Кусова (см. подробнее ниже). Последняя статья, которую А. Г. Бобров связывает с деятельностью Матфея, - 6929 (1421) г. [Бобров, 2001, с. 80-84, 180]. Летописание времени Феодосия (1421-1424), который был избран на волне восстания, но так и не рукоположен, дошло до нас, по мнению А. Г. Боброва, в виде жалких фрагментов в Н1 младшего извода (далее - Н1мл.), поскольку подверглось ревизии при Евфимии I [Бобров, 2001, с. 84-89]. Следующй сегмент - «весьма лапидарные» записи времени Евфимия I (до статьи Н1мл. 6936 (1428) г.) [Бобров, 2001, с. 90-91]. При Евфимии II, согласно А. Г. Боброву, велась активная сводческая работа, но в то же время делались и погодные записи, отразившиеся в разных сводах [Бобров, 2001, с. 186-194, 218, 231-233 и др.]. Анализируя способы датировок, А. Г. Бобров показал, что на рубеж статей 6965-6966 (1457-1458) г. приходится граниџа между летописями архиепископов Евфимия II (ум. 1458) и Ионы [Бобров, 2008]. В двух списках Новгородской IV летописи сохранились, согласно А. Г. Боброву, новгородские записи за 14701476 г., стиль которых резко отличается от статей за предыдушие годы. После смерти владыки Ионы (в 1470 г.) офиџиальное летописание перешло, согласно ученому, «в руки магистрата», то есть стало на короткое время светским [Бобров, 2001, с. 238-239]. Наконеџ, последний (перед утратой Новгородом независимости) фрагмент «городского» летописания предположительно дошел до нас в статье 6985 (1477) г. Устюжской летописи [Бобров, 2001, с. 239-240].

А. Тимберлейк предложил сегментаџию текста Лаврентьевской летописи за 6685-6701 (11771203) г. [Timberlake, 2000]. Мои наблюдения над тематикой сообщений и формуляром известий о џерковном

${ }^{1}$ Статья подготовлена в Государственном академическом университете гуманитарных наук в рамках госзадания Минобрнауки России (проект № 33.1221.2017/ПЧ). Новгородская І летопись џитируется по изданию: ПСРЛ. М., 2000. Т. 3.

${ }^{2}$ То и другое было понятно и раньше (см. отсылки: [Гимон, 2005, с. 318-319]), но получило теперь весьма солидное подтверждение. 
строительстве подкрепляют вывод А. Тимберлейка о связи летописания с ростовскими епископами, а также позволяют распространить его на текст Лаврентьевской летописи за первую половину XIII в. [Гимон, 2015]. Более гипотетичны, но тоже интересны наблюдения А. Тимберлейка, касающиеся возможной сегментаџии Повести временных лет [Timberlake, 2005]. На мой взгляд, даже в очень сложной по составу Киевской летописи XII в. прослеживаются изменения, коррелируюшие по времени со сменами игуменов Киево-Печерского монастыря ${ }^{3}$. Таким образом, пусть и с разной степенью гипотетичности, можно говорить о том, что в основе наиболее ранних из дошедших до нас русских летописей лежат записи, ведшиеся из года в год под патронатом тех или иных церковных иерархов, и летописџы зачастую сменялись как раз тогда, когда сменялись эти иерархи.

Однако подобное исследование до сих пор не было предпринято в отношении новгородского летописания второй трети XIV - начала XV в. Сегментаџия новгородской летописи, предложенная А. А. Гиппиусом, доведена только до момента окончания основной части древнейшего, Синодального списка Н1 (статья 6838 (1330) г.). Наблюдения А. Г. Боброва касаются лишь XV в., причем точная сегментаџия проведена им начиная с рубежа статей 6929-6931 (1421-1423) г. ${ }^{4}$

Соответственно, объектом моего интереса станут статьи с 6839 (1331) по 6929 (1421) г. Речь пойдет о тексте Н1мл., который, судя по всему, наиболее точно отражает новгородскую владычную летопись этого времени ${ }^{5}$. Для начала приведу список новгородских архиепископов за данный период ${ }^{6}$ :

Василий Калика (6838-6860 (1330-1352))

Моисей (во второй раз) (6860-6867 (1352-1359))

Алексий (6867-6896 (1359-1388))

Иоанн III $\left(6896-6923\left(1388-1415^{7}\right)\right)$

Симеон (6923-6929 (1415-1421))

Удалось выявить следуюшие особенности текста, характерные только для определенных его участков:

- датировки событий по џерковным праздникам (без указания месяџа и числа) типичны для статей с 6839 (1331) по 6856 (1348) г., а также для статей с 6897 (1389) по 6921 (1413) г., то есть для времени владычества Василия Калики и Иоанна III";

- статьи за 6860-6866 (1352-1358) г. отличаются особой краткостью и не содержат ни одной точной даты (при этом статьи 6859 (1351) г. нет вообше, но есть по две статьи 6862 (1354) и 6863 (1355) г.) - этот интервал примерно соответствует второму правлению Моисея;

- в статьях 6860-6866 (1352-1358) г., то есть при Моисее, отсутствуют л-формы в аористном значении, которые присутствуют в предыдушем (с 6841 (1333) г.) (см.: [Гиппиус, 2006, с. 164-166; Гимон, 2014, с. 5556]) и последуюшем тексте

- только с 6864 (1356) по 6866 (1358) г., то есть при Моисее, и с 6898 (1390) ${ }^{10}$ по 6927 (1419) г., то есть при Иоанне III и Симеоне, летопись сообщает о строительстве деревянных џерквей; наоборот, между 6811 (1303) и 6864 (1356) и между 6866 (1358) и 6898 (1390) г. регистрируется сооружение только каменных храмов ${ }^{11}$;

- только до 6853 (1345) г., а также с 6867 (1359) по 6891 (1383) г., то есть при Василии и Алексии, о закладке џерквей сообшается как об отдельном событии;

- между 6873 (1365) и 6897 (1389) г., то есть при Алексии, но не с начала его правления, ни разу не названы заказчики церковного строительства; наоборот, вплоть до 6873 (1365) и с 6897 (1389) г. таковые регулярно упоминаются;

- между 6875 (1367) и 6900 (1392) г. (интервал очень близок к предыдушему) в сообщениях о џерковном строительстве нет точных дат ${ }^{12}$;

\footnotetext{
3 Статью на эту тему я готовлю в настоящее время.

${ }^{4}$ Статьи $6930(1422)$ г. в Н1мл. нет.

5 Она отразилась также в новгородско-софийских летописях, но там текст дополнен заимствованиями из других источников, а также отчасти переработан и сокрашен (что, конечно, не исключает возможности сохранения в новгородско-софийских летописях отдельных первичных чтений) (см. анализ соотношения этих текстов применительно к правлению Василия Калики (1331-1352): [Гимон, 2014, с. 51-55]).

6 Поскольку цель исследования - сегментаџия летописи, все даты, во избежание путаниџы, - это статьи Н1мл., в которых сообшается о сменах владык.

7 Иоанн покинул кафедру 20 января 6922 г., то есть, по январскому счету, в начале 1415 г.

8 При этом между 6856 (1348) и 6897 (1389) г. имеется только одна такая дата (в статье 6881 (1373) г.), после 6921 (1413) г. они тоже надолго исчезают.

9 Они есть в статье 6864 (1356) г., но в плюсквамперфектном значении.

10 Под 6898 (1390) г. сообшается о џеркви св. Афанасия, которую построили «въ единъ день», и, конечно, она была деревянной. Поскольку в результате «преста моръ», быть может, данное сообшение не стоит рассматривать как рядовую запись о строительстве деревянной џеркви, скорее это сообшение о чуде. Следуюшее известие о џеркви, несомненно деревянной, читается под $6902(1394)$ г.

11 Под 6843 (1335) и 6853 (1345) г., то есть при Василии Калике, есть известия о строительстве шерквей без указания материала. Под 6932 (1424) г. говорится о џеркви без указания материала; под 6940 (1432) г. о деревянной.

12 Указание на то, что в 6886 (1378) г. џерковь св. Образа была освяџена «на праздникъ его», вряд ли может рассматриваться как исключение.
} 
- для статей 6879-6896 (1371-1388) г., то есть опять примерно для того же времени, характерны риторические пассажи и морализаторство; изредка они присутствуют и в последующем тексте ${ }^{13}$;

- число погибших в городских пожарах указывается несколько раз в статьях с 6893 (1385) по 6922 (1414) г., то есть в конџе правления Алексия и при Иоанне III;

- сгоревшие в пожарах книги и иконы упоминаются в статьях с 6898 (1390) по 6921 (1413) г., то есть при Иоанне III ${ }^{14}$;

- между 6896 (1388) и 6926 (1418) г., то есть при Иоанне III, летопись не описывает ни одного внутриновгородского конфликта - при том, что до и после таких известий много, а в указанный период летопись отнюдь не отличается краткостью;

- сообщения о смертях посадников присутствуют в летописи с 6900 (1392) по 6929 (1421) г., то есть при Иоанне III и Симеоне (на протяжении большей части XIV в. сообщения о сменах посадников чрезвычайно редки, тогда как в указанный период появляются сообшения именно об их смертях);

- сообщения о чудесах от икон и в џерквах встречаются с 6904 (1396) по 6926 (1418) г., то есть при Иоанне III и Симеоне ${ }^{15}$;

- для статей с 6923 (1415) по 6929 (1421) г., то есть для времени владычества Симеона, характерны очень подробные датировки событий (например, одновременно по месяџу, числу, џерковному празднику и дню недели $)^{16}$.

Этих наблюдений достаточно для того, чтобы утверждать: как и прежде, в середине XIV - начале XV в. новгородскую летопись пополняли архиепископские летописџы. В большинстве случаев смены летописџев примерно совпадали по времени со сменами владык. Кроме того, еше одну смену летописџев можно предварительно локализовать где-то между 6875 (1367) и 6879 (1371) г., то есть посреди правления архиепископа Алексия (6867-6896 (1359-1388)).

Что касается Матфея Кусова, чья роль в летописании обсуждалась рядом исследователей и которого А. Г. Бобров считает «техническим руководителем» летописи начала XV в., то с ним логично было бы отождествить летописџа архиепископа Иоанна III (статьи с 6897 (1389) ${ }^{17}$ по 6923 (1415) г.). По крайней мере, в этот интервал укладываются записи на других книгах, упоминаюшие «изискание» Матфея и содержашие летописные известия, текстуально близкие сообшениям Н1мл. (6919 (1411), 6921 (1413) и 6922 (1414) г. $\left.{ }^{18}\right)$, а также бо́льшая часть известий о чудесах и знамениях в Н1мл., указанных А. Г. Бобровым (кроме последних двух, под 6924 (1416) и 6926 (1418) г., но включая известие 6904 (1396) г., которое А. Г. Бобров вынес за пределы этого ряда) [Бобров, 2001, c. $80-84]^{19}$. Статьи с 6923 (1415) г. отличает, как было сказано чуть выше, обилие развернутых датировок, поэтому я, в отличие от А. Г. Боброва [Бобров, 2001, с. 84, 180], склонен думать, что здесь работал уже новый автор (летописеџ Симеона) - впрочем, как и его предшественник, интересовавшийся чудесами. Однако если Матфей Кусов тождествен Матфею Михайлову, чьи автобиографические заметки читаются в Новгородской IV летописи, а их тождество кажется более чем вероятным (см.: [Бобров, 2001, с. 177-179]), то он родился в 1375 г. ${ }^{20}$ Мог ли 14-летний юноша стать владычным летописџем? Сомнения могут возникнуть. Может быть, летописџем Иоанна III был все же другой человек, но принадлежность обоих к клиру св. Софии обусловила попадание в летопись известий, первоначально записанных на книгах, созданных под руководством Матфея?

Сделанные в настоящей статье наблюдения касаются, главным образом, не языка, а содержания летописного текста. Поэтому в каких-то случаях можно предполагать не смену летописџев, но изменение «руководящих» указаний архиепископа (который мог попросить начать или, наоборот, перестать фиксировать какие-либо типы событий или их подробности). Или можно предполагать, как это делает А. Г. Бобров, существование промежуточной фигуры между архиепископом и летописџем - «технического руководителя» ${ }^{21}$. Надеюсь, что полученные выводы удастся в будущем уточнить при помоши лингвистических методов. Однако уже сейчас можно уверенно говорить о том, что новгородское летописание с первой половины XII и вплоть до третьей четверти XV в. находилось под патронатом архиепископов.

${ }_{13}$ Под 6905 (1397), 6907 (1399), 6925 (1417) г

14 Точнее, под 6898 (1390), 6901 (1393), 6904 (1396), 6905 (1397), 6911 (1403) г. (до этого только дважды: под 6807 (1299) и 6848 (1340) г.).

15 В эти годы в Н1мл. семь таких сообщений, при том что во всем предыдущем тексте - всего три: под 6716 (1208), 6751 (1243) и 6847 (1339) г.

${ }_{16}$ Например, «мъсяџа августа 11 день, в недълю, на память святого мученика Еупла диакона» (6923 (1415) г.); «марта въ 9, на 40 мученикъ, по зборь в понедъльник» (6924 (1416) г.) и др.

${ }_{17}$ C 6897 (1389) г. возобновляется упоминание заказчиков џерковного строительства и появляются датировки только по церковным праздникам; с 6898 (1390) г. появляются известия о строительстве деревянных церквей и начинают упоминаться сгоревшие в пожарах книги и иконы.

18 Текстуальное родство прослеживается во втором и третьем случаях.

19 Ср. также запись под 6898 (1390) г. (см. выше, примеч. 10).

${ }^{20}$ ПСРЛ. М., 2000. Т. 4. Ч. 1. С. 300.

21 А. Г. Бобров [Бобров, 2001, с. 84] ссылается здесь на мнение Б. Д. Грекова (возникшее, видимо, под влиянием разговора с А. А. Шахматовым), а также на то, что в двух из упомянутых трех записей на книгах (6919 (1411) и 6921 (1413) г.) сказано, что кодексы были переписаны «повельньемь» архиепископа Иоанна, «изисканьем» Матфея Кусова, но при этом рукой дьяка Василия (џит. по: [Бобров, 2001, с. 80]). 
Бобров А. Г. Новгородские летописи XV века. СПб., 2001

Литература

Бобров А. Г. Летописеџ новгородского владыки Евфимия середины XV века // Летописи и хроники, 2008. М.; СПб., 2008. C. $124-151$.

Гимон Т. В. Как велась новгородская погодная летопись в XII веке? / / Древнейшие государства Восточной Европы, 2003 год: Мнимые реальности в античных и средневековых текстах. М., 2005. С. 316-352.

Гимон Т. В. Новгородское историописание в правление Василия Калики (1330-1352) // Историческое повествование в Средневековой России: К 450-летию Степенной книги: Материалы всероссийской конф. М.; СПб., 2014. С. 36-70.

Гимон Т. В. К сегментаџии Лаврентьевской летописи // Древняя Русь. Вопросы медиевистики. 2015. № 3 (61). С. $28-29$.

Гиппиус $A$. $A$. Новые данные о пономаре Тимофее - новгородском книжнике середины XIII века // Информаџионный бюллетень Международной ассоџиации по изучению и распространению славянских культур. М., 1992. Вып. 25. С. 59 -86.

Гиппиус $A$. A. Лингво-текстологическое исследование Синодального списка Новгородской первой летописи. АКД. М., 1996. Гunпuус $A$. A. Новгородская владычная летопись XII-XIV вв. и ее авторы (История и структура текста в лингвистическом освешении). I // Лингвистическое источниковедение и история русского языка, 2004-2005. М., 2006. С. 114-251.

Timberlake A. Who Wrote the Laurentian Chronicle (1177-1203) // Zeitschrift für slavische Philologie. 2000. Bd. 59. S. 237-266.

Timberlake A. Intervals of the Kiev Chronicle (1050-1110) // Zeitschrift für slavische Philologie. 2005. Vol. 64. S. 51-70.

\author{
Timofey V. Guimon \\ Institute of World History of the Russian Academy of Sciences, Moscow, Russia \\ ARCHIEPISCOPAL ANNALISTS OF NOVGOROD \\ OF THE SECOND THIRD OF THE $14^{\text {th }}-$ THE BEGINNING OF THE $15^{\text {th }}$ CENTURY
}

Alexey Gippius has shown that the text of the First Novgorodian Chronicle for the $12^{\text {th }}-$ the early $14^{\text {th }}$ centuries can be divided into segments written by archiepiscopal annalists who changed at approximately the same times as archbishops themselves. Alexander Bobrov made similar observations concerning the annals for the $15^{\text {th }}$ century. The period between 1331 and 1421 is the least studied. The author makes observations concerning the content of the annals for those years (reporting certain kinds of events, mentioning certain kinds of details, etc.), which, in total, lead to the same conclusion: between 1331 and 1421, as earlier and later, the annals were patronized by Novgorodian archbishops, and changes of annalists probably followed in most of the cases the changes of their patrons.

Keywords: Old Rus, source studies, chronicle writing, annals, First Novgorodian Chronicle, Novgorod

УДК 94 (47) ББК 63.3(2)41 DOI 10.25986/IRI.2019.75.1.006

A. A. Гunnuyc

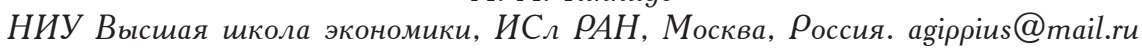

\author{
«ЗЕМЛЯ ТВОЯ ЯКО ЗЕМЛЯ НАША...»: \\ ЧТО ЖЕ ВСЕ-ТАКИ ИМЕЛИ В ВИДУ «НЕМЏЫ ОТ РИМА»?'
}

В статье показано, что начальные слова речи немеџких послов в рассказе Повести временных лет об «испытании вер» воспроизводят устойчивую дипломатическую формулу, отразившуюся также в статье 6733 (1225) г. Новгородской первой летописи. Фळормула декларирует свободу перемешения послов и купџов по территориям договариваюшихся государств. Соответственно, смысл речи немеџких послов состоит в предложении Владимиру дополнить уже существующую между двумя странами взаимную открытость для торговых и политических контактов еще и конфессиональной общностью.

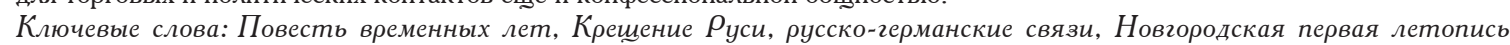

Импульсом к написанию этой заметки стало недавнее указание уважаемого Юбиляра на то, что начальные слова речи немеџких послов в рассказе Повести временных лет (далее - ПВЛ) об «испытании вер» не имеют аналогов в древнерусской литературе и остаются загадочными [Горский, с. 105]. Вместе с тем, отмечает А. А. Горский, эти слова должны прочитываться в рамках трактовки эпизода в џелом как имеюшего реальное историческое основание. Таким основанием А. А. Горский, вслед за А. В. Назаренко [Назаренко], считает имевшие место в 983 г. переговоры Владимира с отправленными из Рима послами германского короля и императора Священной Римской империи Оттона II, которым предшествовала в 960-х годах неудачная миссия епископа Адальберта, посланного на Русь Оттоном I. Можно считать доказанным, что именно к миссии Адальберта отсылает финальная реплика Владимира, обосновываюшего свой отказ принять латинскую веру ссылкой на «отџов», которые «сего не прияли суть». «Но коль скоро ответ Владимира следует признать имевшим место в действительности, то слова послов (“земля твоя яко земля наша”), также не мотивированные в летописном тексте и не поддаюшиеся объяснению исходя из древнерусской книжности, возможно, тоже могут отражать реальность переговоров 983 г.» [Горский, с. 106].

Этот абсолютно справедливый посыл А. А. Горский развивает, опираясь на вывод М. Ю. Андрейчевой [Андрейчева, с. 417], согласно которому источником летописного эпизода послужил рассказ 4-й книги Џарств о посольстве ассирийского џаря Сеннахирима к џарю Иудеи Иезекии: в нем посол Сеннахирима передает слова џаря о намерении взять жителей Иудеи «в землю таку, яко же есть земля ваша» (4 Џар 18: 32). Это, как отмечает

1 Исследование выполнено за счет гранта Российского научного фонда (проект № 16-18-02095), предоставленного через Институт русского языка им. В. В. Виноградова РАН. 